\title{
REMOVAL OF SCLERAL EXPLANT ELEMENTS: A 10-YEAR RETROSPECTIVE STUDY
}

\author{
J. DEUTSCH, R. K. AGGARWAL, E. M. EAGLING \\ Birmingham
}

\section{SUMMARY}

There are several studies in the American literature on the incidence and causes of retinal redetachment following removal of explants. This is, to our knowledge, the first such study from Britain and differs in its findings from the American experience. The reason for removal of explants, the time of removal after initial detachment surgery and the consequences of removal were reviewed for the 10-year period from 1980 to 1990 . During this period 1898 retinal detachment operations were performed at this centre, with an explant removal rate of $3.2 \%(61$ eyes). Extrusion of the element was the cause in $74 \%$. Of these $8 \%$ subsequently suffered a redetachment. In two eyes no retinal break was identified at initial surgery. Both of these suffered a redetachment following removal of the explant. Contrary to previous reports, redetachment was not related to short periods of explant or to infection of the explant. This study suggests that explant removal is a safe procedure. However, there is a significant risk of redetachment after explant removal if no breaks are identified at the time of initial surgery.

At the present time most retinal detachment operations involve the use of scleral explants. Their removal due to pain, infection or extrusion, although infrequent, may be unavoidable and serious complications may ensue.

Several studies have been published in the American literature on the incidence and factors leading to explant removal and the subsequent incidence and causes of retinal redetachment. ${ }^{1-3}$ Reported rates of explant removal vary from $1.3 \%$ to $24 \% .^{2-5}$ Reasons for their removal include extrusion, infection, pain or foreign body sensation, diplopia or visual distortion, recurrent subconjunctival haemorrhages and scleritis. ${ }^{2-4,6}$ Retinal redetachment following conventional surgery without removal of explant is reported to occur in 5-10\% of cases. Retinal redetachment following explant removal has been variously reported as between $4 \%$ and $47 \%$ (follow-up rang-

Correspondence to: John Deutsch, Birmingham and Midland Eye Hospital, Church Street, Birmingham B3 2NS, UK. ing from 6 months to 4 years). ${ }^{1-3}$ One study (with a 4-year follow-up period $)^{1}$ reported the risk of redetachment following explant removal to be greatest if the explant was removed within a month of initial detachment surgery (47\% of redetachments), most redetachments $(70 \%)$ having occurred in patients subjected to explant removal within 3 months of initial surgery. This study examines data from a 25-year period and includes treatment methods no longer in common usage (diathermy, scleral dissection and polyethylene tubing explants).

The Committee on Retinal Detachment from the American Academy of Ophthalmology and Otolaryngology $(1965)^{7}$ suggested a minimum of 6 months follow-up for the establishment of an anatomical cure in retinal detachment surgery.

We present the results of a 10-year audit from a large ophthalmic unit and examine the incidence and causes of retinal redetachment following explant removal.

\section{SUBJECTS AND METHODS}

All patients undergoing retinal detachment surgery with a scleral explant at the Birmingham and Midland Eye Hospital between the years 1980 and 1990 were identified from the theatre register. Those requiring explant removal were identified from the same source and from the minor operation record book in the outpatients department. The clinical notes of all those undergoing scleral explant removal were examined and selected in accordance with the following criteria:

1. The primary retinal detachment was considered to be rhegmatogenous (whether or not a break was found).

2. Retinal attachment was complete at the time of explant removal.

3. No further procedure was undertaken at the time of explant removal.

4. There was at least 6 months follow-up after explant removal.

5. Patients requiring vitrectomy were excluded. 
Table I. Removal of explants

\begin{tabular}{llcl}
\hline & Attached & Redetached & Total \\
\hline Total & 56 & 5 & 61 \\
Sex & & & \\
$\quad$ Male & 28 & 1 & 29 \\
$\quad$ Female & 28 & 4 & 32 \\
Age (yr) & & & \\
$\quad$ Range & $18-91$ & $22-81$ & $18-91$ \\
Mean & 59 & 55 & 59 \\
\hline
\end{tabular}

The data were analysed with respect to:

1. Sex.

2. Age.

3. Type of break.

4. Type of explant (all either silicone sponge or solid silicone straps with or without additional elements).

5. Time from original surgery to explant removal.

6. Reasons for removal of the explant.

7. Follow-up time following explant removal.

8. Time to and reasons for any redetachment.

Statistical analysis was performed with Fisher's exact test and the Mann-Whitney $U$-test as appropriate.

\section{RESULTS}

In the 10 -year period from 1980 to 1990,1898 retinal detachment operations were performed requiring scleral explants. A hospital policy existed during this period of soaking explants in gentamicin just prior to use, with injection of gentamicin into sponge explants. Sixty-one eyes were identified within the study period requiring the removal of an explant (3.2\%). The mean age of those undergoing explant removal was 58.5 years (range 18-91 years: Table I) and there was no significant sex difference (males 47\%, females 53\%). Follow-up time ranged from 6 months to 9 years following removal of explant (mean 2.63 years).

\section{Reason for Removal}

The factors necessitating removal of the explant included acute infection (inflamed eye, culture-positive with or without extrusion), extrusion (quiet eye with conjunctival thinning or dehiscence), diplopia and scleritis. Extrusion was by far the most common reason for removal of the explant ( $74 \%$ of cases), followed by infection $(20 \%)$ (Table II). The redetachment rate after explant removal was 5 of 61 eyes $(8.2 \%)$.

Table II. Factors leading to explant removal

\begin{tabular}{|c|c|c|c|}
\hline & Attached & Redetached & Total \\
\hline Total & $56(92 \%)$ & $5(8 \%)$ & $61(100 \%)$ \\
\hline Infected* & 11 & 1 & $12(20 \%)$ \\
\hline Extrusion* & 42 & 3 & $45 \quad(74 \%)$ \\
\hline Diplopia & 2 & 0 & $2(4 \%)$ \\
\hline Scleritis & 1 & 1 & $2 \quad(3 \%)$ \\
\hline
\end{tabular}

$*_{p}=0.48$, Fisher exact test.
Table III. Duration of explant (time from primary surgery to removal of explant in months)

\begin{tabular}{llcl}
\hline Time (months) & Attached* & Redetached* & Total \\
\hline Total & $56(92 \%)$ & $5(8 \%)$ & $61(100 \%)$ \\
$<6$ & 12 & 0 & $12(20 \%)$ \\
$6-12$ & 17 & 0 & $17(28 \%)$ \\
$13-24$ & 9 & 3 & $12(20 \%)$ \\
$>24$ & 18 & 2 & $20(20 \%)$ \\
\hline
\end{tabular}

${ }^{*} p=0.12$, Mann-Whitney $U$-test.

Only 1 of 12 eyes requiring removal of the explant as a result of acute infection redetached compared with 3 of 42 $(6.7 \%)$ that extruded. This was not statistically significant $(p>0.1$, Fisher exact test). Infection as a cause for removal of the explant was more common for solid silicone explants as against sponge explants $(27 \%$ and $13 \%$ respectively).

\section{Duration of Explant}

Table III shows the relationship between duration of explant and redetachment.

Although almost $20 \%$ of explants were removed within 6 months of primary detachment surgery none of these redetached. There was no significant trend relating time between primary detachment surgery and removal of the explant to whether a redetachment occurred $(p=0.12$, Mann-Whitney $U$-test). Redetachments occurred even when the primary surgery had taken place 2 or more years earlier.

\section{Type of Break}

When considering the type of retinal break responsible for the original retinal detachment (see Table IV), $41 \%$ had single breaks, $26 \%$ multiple breaks, $18 \%$ had a dialysis, $12 \%$ a round hole, and in 3\% (2 cases) no breaks were found. Both cases in which no breaks were found at primary surgery redetached on removal of the explant. This was found to be statistically significant $(p=0.01$, Fisher exact test). The redetachment rate for the dialysis group was higher than that for the whole group but was not statistically significant $(p=0.37$, Fisher exact test).

\section{Reasons for Redetachment}

The retina redetached in 5 eyes (see Table V). Two of these were aphakic eyes, in one of which no breaks were identified at the time of initial surgery. The second developed an apparently new ' $U$ ' tear, 6 clock hours from the site of the

Table IV. Type of break identified at original surgery

\begin{tabular}{lllrl}
\hline & Attached & Redetached & \multicolumn{2}{c}{ Total } \\
\hline Total & $56(92 \%)$ & $5(8 \%)$ & $61(100 \%)$ \\
Single 'U' tear & 24 & 1 & 25 & $(41 \%)$ \\
Round hole & 7 & 0 & 7 & $(12 \%)$ \\
Multiple breaks & 15 & 1 & 16 & $(26 \%)$ \\
Dialysis $^{\text {a }}$ & 10 & 1 & 11 & $(18 \%)$ \\
None* & 0 & 2 & 2 & $(3 \%)$ \\
\hline
\end{tabular}

${ }^{\mathrm{a}} p=0.37$, Fisher exact test.

$* p=0.01$, Fisher exact test. 
Table V. Summary of cases suffering redetachment after removal of the explant

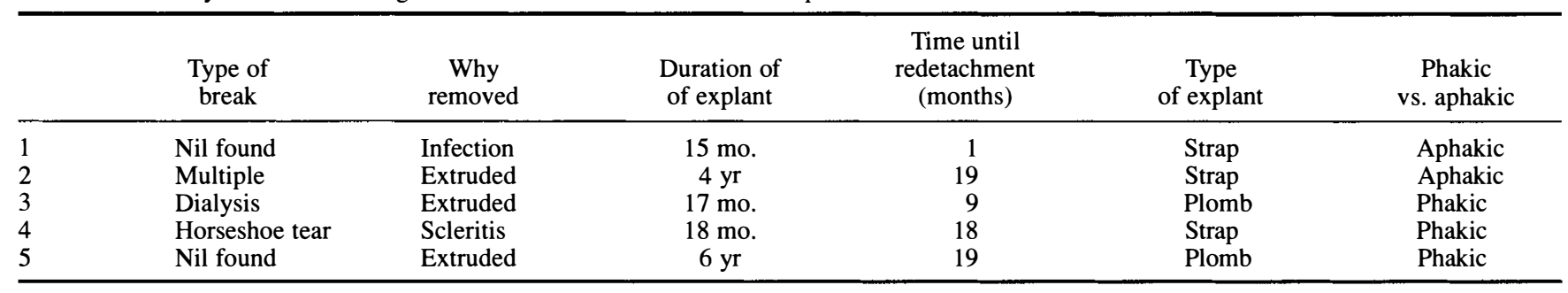

group of round breaks which were seen at initial surgery. This case also had proliferative vitreoretinopathy at presentation with the redetachment.

The third and fourth cases redetached in an area relating to the initial break, one with a ' $U$ ' tear and recorded vitreoretinal adhesion, the other with a large traumatic dialysis.

In the last case the original surgery was performed for a localised upper-half retinal detachment with no identifiable break. After removal of the explant the eye developed a redetachment of the lower retina with an apparently new ' $U$ ' tear at the 6 o'clock retinal periphery.

Thus of 5 eyes suffering redetachment after explant removal, 2 developed apparently new breaks. The 2 cases in this group in which no breaks were found at initial surgery both redetached following explant removal with identifiable breaks ( $p=0.01$, Fisher exact test). All of these 5 cases had subsequent successful anatomical repair.

\section{DISCUSSION}

In this study extrusion is the most common cause for explant removal (74\%) rather than infection (20\%). Other series report a higher incidence of acute infection $\left(30 \%,{ }^{2}\right.$ $\left.33 \%,{ }^{3} 49 \%^{1}\right)$. This may be attributable to the present study being more recent, with improved explant material and routine intraoperative use of antibiotics. It is appreciated that our actual extrusion rate may be higher as some spontaneous events will inevitably have been missed despite efforts to prevent this. The redetachment rate following explant removal of $8.2 \%$ over a mean of 2.6 years is lower than in other series ( $47 \%$ in 4 years, ${ }^{1} 14 \%$ between 1 week and 2 years ${ }^{3}$ ).

Infection as a reason for explant removal was reported as a major contributing factor to redetachment in these studies and their higher rate of infected explants may explain this difference in detachment rates. Hitchings et $a{ }^{8}{ }^{8}$ emphasised the problems associated with infection following scleral explant procedures with trans-scleral cryotherapy. In that series $2.4 \%$ of cases ( 10 eyes) required removal of explant within 2 weeks of surgery as a result of serious infection. Seven cases had signs of intraocular inflammation all having required drainage of subretinal fluid at the time of initial surgery. This threat of early explant infection was shown to be preventable by the use of peroperative antibiotics, ${ }^{9}$ which eliminated early infection and reduced late infection to $1.5 \%$.

In previous reports a higher risk of redetachment after explant removal was noted if initial explant time was less than 6 months. ${ }^{1-3}$ Our series did not identify any such case. None of the 29 cases $(48 \%)$ requiring explant removal within 12 months of explant redetached. In 3 cases of redetachment the time from original surgery to explant removal was between 1 and 2 years, and in 2 cases more than 2 years ( 4 and 6 years). Redetachment in this series does not appear to be related to short explant times prior to explant removal. Similarly, the time to redetachment following explant removal is very variable: in our series between 1 and 19 months after explant removal (see Table V). This was also noted by others. ${ }^{1}$

In the 5 cases of redetachment following explant removal only one (case 5, Table V) appeared to have a new break unrelated to the previous detachment. This occurred 19 months following the removal of an extruding silicone sponge explant. In the other cases ongoing vitreoretinal traction and incomplete cryotherapy could have played a role in causing the redetachment, although only one of these redetached within 6 months of explant removal.

\section{CONCLUSION}

Our results differ from previous reports in some important respects:

1. Extrusion was a more common reason for explant removal than infection.

2. Short intervals between retinal detachment surgery and removal of the explant ( $<6$ months) did not appear to be related to an increased risk of redetachment. Redetachments occurred even after 6 years of explant.

3. The redetachment rate was $8.6 \%$ following explant removal (mean follow-up period 2.6 years).

4. The risk of redetachment following explant removal was significantly increased if no breaks were identified at initial detachment surgery. This has not been reported previously.

Key words: Detachment, Explants, Removal, Scleral.

\section{REFERENCES}

1. Lindsey P, Pierce L, Welch R: Removal of scleral explant elements. Arch Ophthalmol 1983, 101: 570-3.

2. Hilton $\mathrm{G}$ and Wallyn R: The removal of scleral buckles. Arch Ophthalmol 1978, 96: 2061-3.

3. Schwartz PL and Pruett RC: Factors influencing retinal redetachment after removal of explant elements. Arch Ophthalmol 1977, 95: 804-7.

4. Wiznia RA: Removal of solid silicone rubber explants after retinal detachment surgery. Am J Ophthalmol 1983, 95: 495-7.

5. Russo CE and Ruiz RS: Silicone sponge rejection: early and late complications in retinal detachment surgery. ArchOphthalmol 1971, 85: 647-50. 
6. Fison $\mathrm{P}$ and Chignell A: Diplopia after retinal detachment surgery. Br J Ophthalmol 1987, 71: 521-5.

7. Pischel DK (ed): Retinal Detachment. A manual of the American Academy of Ophthalmology and Otolaryngology. Omaha: Douglas Publishing Co., 1965: 9.
8. Hitchings RA, Levy IS, Chignell AH: Acute infection after retinal detachment surgery. $\mathrm{Br} J$ Ophthalmol 1974, 58: 588-90.

9. Lean JS and Chignell AH: Infection following retinal detachment surgery. Br J Ophthalmol 1977, 61: 593-4. 